OPEN ACCESS

Edited by:

Antongiulio Faggiano,

Sapienza University of Rome, Italy

Reviewed by:

Letizia Canu,

University of Florence, Italy

Attila Patocs,

Semmelweis University, Hungary

${ }^{*}$ Correspondence:

Diana Borges Duarte diana.sbduarte@gmail.com

Specialty section:

This article was submitted to

Cancer Endocrinology,

a section of the journal

Frontiers in Endocrinology

Received: 22 September 2020 Accepted: 01 March 2021

Published: 17 March 2021

Citation:

Duarte DB, Ferreira L, Santos $A P$, Costa C, Lima J, Santos C, Afonso M,

Teixeira MR, Carvalho $R$ and

Cardoso MH (2021) Case Report:

Pheochromocytoma and

Synchronous Neuroblastoma in a

Family With Hereditary

Pheochromocytoma Associated With a MAX Deleterious Variant.

Front. Endocrinol. 12:609263. doi: 10.3389/fendo.2021.609263

\section{Case Report: Pheochromocytoma and Synchronous Neuroblastoma in a Family With Hereditary Pheochromocytoma Associated With a MAX Deleterious Variant}

\author{
Diana Borges Duarte ${ }^{1 *}$, Lia Ferreira ${ }^{1}$, Ana P. Santos ${ }^{2}$, Cláudia Costa ${ }^{2}$, Jorge Lima ${ }^{3,4,5}$, \\ Catarina Santos $^{6}$, Mariana Afonso ${ }^{7}$, Manuel R. Teixeira ${ }^{6,8}$, Rui Carvalho $^{1}$ and \\ Maria Helena Cardoso ${ }^{1}$ \\ ${ }^{1}$ Department of Endocrinology, Centro Hospitalar Universitário do Porto (CHUP), Porto, Portugal, ${ }^{2}$ Department of \\ Endocrinology, Instituto Português de Oncologia Francisco Gentil (IPOFG), Porto, Portugal, ${ }^{3}$ i3S - Instituto de Investigação e \\ Inovação em Saúde, Universidade do Porto, Porto, Portugal, ${ }^{4}$ Ipatimup - Institute of Molecular Pathology and Immunology \\ of the University of Porto, Porto, Portugal, ${ }^{5}$ Faculty of Medicine, University of Porto, Porto, Portugal, ${ }^{6}$ Department of \\ Genetics, Instituto Português de Oncologia Francisco Gentil (IPOFG), Porto, Portugal, ${ }^{7}$ Department of Pathology, Instituto \\ Português de Oncologia Francisco Gentil (IPOFG), Porto, Portugal, ${ }^{8}$ Biomedical Sciences Institute, University of Porto, \\ Porto, Portugal
}

Introduction: Pheochromocytomas are rare catecholamine-producing neuroendocrine tumours arising from chromaffin cells of the adrenal medulla or extra-adrenal sympathetic paraganglia. Recent studies have indicated that up to $40 \%$ of pheochromocytomas could be attributable to an inherited germline variant in an increasing list of susceptibility genes. Germline variants of the MYC-associated factor (MAX) gene have been associated with familial pheochromocytomas and paragangliomas with an autosomal dominant pattern of inheritance, a median age at onset of 33 years and an overall frequency estimated at $1.9 \%$. We describe a deleterious MAX variant associated with hereditary pheochromocytoma in a family with four affected individuals.

Case presentation: The first patient presented with bilateral pheochromocytoma in 1995; genetic testing was proposed to his oldest son, when he was diagnosed with a bilateral pheochromocytoma with a synchronous neuroblastoma. Upon the identification of the MAX variant c.97C>T, p.(Arg33Ter), in the latter individual, his two siblings and their father were tested and the same variant was identified in all of them. Both siblings were subsequently diagnosed with pheochromocytoma (one of them bilateral) and choose to remain on active surveillance before they were submitted to adrenalectomy. All the tumours secreted predominantly norepinephrine, accordingly to the typical biochemical phenotype ascribed to variants in the MAX gene.

Conclusion: This case series is, to our knowledge, the one with the largest number of individuals with hereditary pheochromocytoma with a deleterious MAX variant in the same family. It is also the first case with a synchronous pheochromocytoma and neuroblastoma 
in carriers of a MAX deleterious variant. This report draws attention to some ill-defined features of pheochromocytoma and other malignancies associated with a MAX variant and highlights the importance of understanding the genotype-phenotype correlation in hereditary pheochromocytoma and the impact of oriented genetic testing to detect, survey and treat patients and kindreds at risk.

Keywords: MAX gene, pheochromocytoma, hereditary, neuroblastoma, paraganglioma

\section{INTRODUCTION}

Pheochromocytomas are rare catecholamine-producing neuroendocrine tumours arising from chromaffin cells of the adrenal medulla ( $80 \%$ to $85 \%$ of the cases) or extra-adrenal sympathetic paraganglia ( $15 \%$ to $20 \%$ of the cases), the latter also referred as extra-adrenal pheochromocytomas or paragangliomas (1).

In general outpatient clinics, the prevalence of pheochromocytoma in patients with hypertension is $0.1-0.6 \%$ (24). In recent years there has been an increase in the number of incidentally diagnosed cases, which seems to be related to the greater availability of imaging studies in clinical practice (1). Although epidemiological data on incidence rate is scarce, a recent Dutch study, by Berends et al. (5), found a significant increase in the age standardized incidence rate of pheochromocytomas from 0.29 to 0.46 per 100, 000 person-year between 1995 and 2015.

Recent studies have indicated that up to $40 \%$ of pheochromocytomas could be attributable to an inherited germline variant in an increasing list of susceptibility genes (6), which can be grouped into three clusters: pseudohypoxia group (VHL, SDHA, SDHB, SDHC, SDHD, SDHAF2, FH and EPAS1), kinase signalling group (RET, NF1, TMEM127, MAX and HRAS) and Wnt signalling group (CSDE1 and MAML3) (7). On this basis, international recommendations suggest that it is essential to offer genetic testing to every patient with a pheochromocytoma as a specific inherited mutation impacts surveillance and monitoring for tumour recurrence, therapeutic approaches, and family screening (7-12).

MAX (MYC-associated factor) is a gene associated with regulation of cell proliferation, differentiation, and death (13). Since 2011 (14), germline mutations of the MAX gene have been associated with familial pheochromocytomas and paragangliomas with an autosomal dominant pattern of inheritance and a median age at onset of 33 years (range 13-58 years) $(7,11)$. The overall frequency is estimated at $1.9 \%$ and no reliable penetrance estimations are available. The adrenal location is the most common and multifocal tumours are frequent $(11,15)$. As a kinase signalling pheochromocytoma, it represents a more ultimate cell differentiation with expression of phenylethanolamine N-methyltransferase (PNMT) as the most prominent characteristic, allowing synthesis of epinephrine from norepinephrine (7).

We report a family with hereditary pheochromocytoma carrying a $M A X$ deleterious variant in four affected relatives.

\section{CASE REPORT}

The patients gave their written consent to sample collection, genetic testing, and the use of genetic test data for the purposes of research. Written informed consent for publication of their clinical details and/or clinical images was obtained from the patients and relative of the patient 2 .

\section{Patient 1 - The Index Case}

In November 2010, a 27-year old male, the oldest of the three children of patient 2, was admitted to our hospital for evaluation of an inguinal pain. He had no medical or medication history and was a competitive swimmer. He reported a 3 month-history of inguinal pain, resting tachycardia and a weight loss of $10 \mathrm{~kg}$ in the last year that he ascribed to intense exercise and diet. At his first observation on the internal medicine ward, his blood pressure (BP) was $200 / 100 \mathrm{mmHg}$ with a resting heart rate of 140bpm (sinus tachycardia with signs of left ventricular volume overload on EKG) but presented an otherwise normal physical examination. Whole body (WB)-CT scan revealed a posterior mediastinal mass $(59 \times 80 \mathrm{~mm}$ ) paravertebral to T9-T11 vertebral bodies, bilateral hypervascular adrenal lesions $(46 \times 39 \mathrm{~mm}$ and $15.5 \mathrm{~mm}$ on the left and $80 \times 110 \mathrm{~mm}$ on the right) and a retroperitoneal periaortic and peri-common iliac artery lesion $(135 \times 185 \mathrm{~mm})$ with an extensive encasement of this vessel with a marked compression of the venous structures (Figure 1).

A biopsy of the retroperitoneal mass was performed and was suggestive of a paraganglioma (tumour cells reactive with chromogranin and synaptophysin); for this reason, Endocrinology observation was required. The hormonal workup revealed catecholamine hypersecretion (Table 1), ${ }^{123} \mathrm{I}$ metaiodobenzylguanidine $\left({ }^{123} \mathrm{I}-\mathrm{MIBG}\right)$ showed left adrenal and para-aortic and common iliac trace uptake and on echocardiogram there were signs of catecholaminergic cardiomyopathy with severe left ventricular dysfunction (ejection fraction $\sim 20 \%$ ).

After multidisciplinary review of the case, a metastatic pheochromocytoma and paraganglioma were presumed and surgery was proposed. He needed hospitalization for preoperative blood pressure and chronotropic control (despite treatment with phenoxybenzamine $100 \mathrm{mg}$, amlodipine $10 \mathrm{mg}$, propranolol $120 \mathrm{mg}$ and amiodarone $200 \mathrm{mg}$ daily).

$\mathrm{He}$ underwent bilateral adrenalectomy with incomplete resection of tumoral mass from the left iliac vessels in February 2011 and pathology was consistent with medullar hyperplasia on the right adrenal gland, and pheochromocytoma with evidence of 

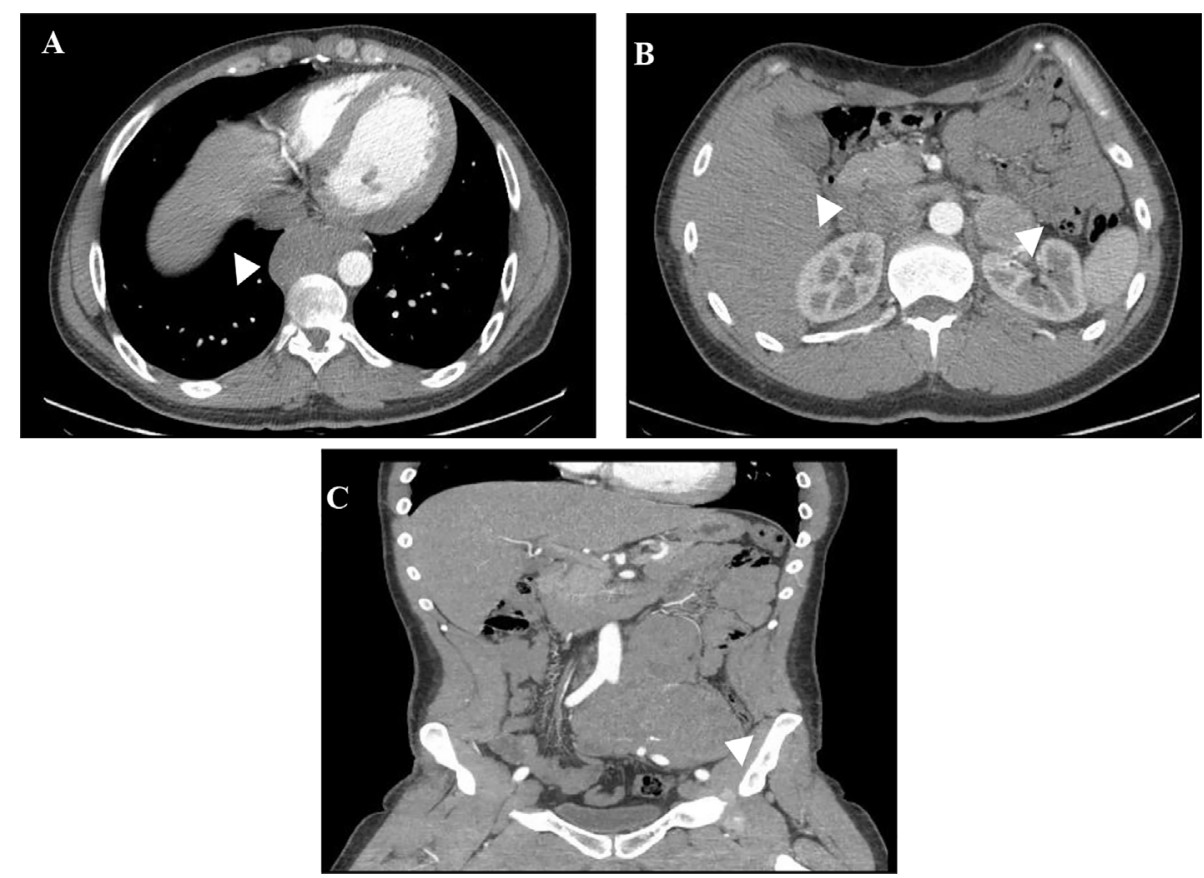

FIGURE 1 | WB-CT scan at diagnosis of patient 1. Posterior mediastinal mass paravertebral to T9-T11 vertebral bodies (A), bilateral adrenal lesions (B) and periaortic and peri-common iliac artery lesion with an extensive encasement of this vessel (C).

TABLE 1 | Urinary catecholamines and metanephrines (reference range) at presentation and during follow-up of Patient 1.

\begin{tabular}{|c|c|c|c|c|c|c|c|c|}
\hline \multicolumn{3}{|c|}{ At presentation } & \multicolumn{6}{|c|}{ Follow-up } \\
\hline & Metanephrines & $\begin{array}{c}2618 \\
(264-1729 \mathrm{nmol})\end{array}$ & $\begin{array}{c}78 \\
(264-1729 \mathrm{nmol})\end{array}$ & $\begin{array}{c}<52 \\
\text { (52-341ug) }\end{array}$ & $\begin{array}{c}<52 \\
\text { (52-341ug) }\end{array}$ & $\begin{array}{c}<52 \\
(52-341 \mathrm{ug})\end{array}$ & $\begin{array}{c}<52 \\
\text { (52-341ug) }\end{array}$ & $\begin{array}{c}<52 \\
\text { (52-341ug) }\end{array}$ \\
\hline
\end{tabular}

From July'2011 onwards the measurements were performed and kindly provided by the Portuguese Institute of Oncology-Porto.

NM, not measured.

angioinvasion on the left adrenal gland with tumour cells reactive with chromogranin, synaptophysin and S100. The extra-adrenal tumour was suggestive of well differentiated neuroblastoma (tumour cells reactive with neurofilaments, chromogranin, synaptophysin, NSE and S100) with a Ki-67 index of $10 \%$.

On the immediate post-operative period, his blood pressure and his left ventricular ejection fraction normalised and there was no evidence of catecholamine hypersecretion. ${ }^{123}$ I-MIBG performed on April 2011 showed an intense uptake on his left iliac artery.

Due to significant residual tumoral lesions, the patient was referred to the Portuguese Oncology Institute of Porto (IPOFG, Porto). Next generation sequencing (NGS), using the TruSight Hereditary Cancer Panel (Illumina) identified the MAX germline truncating variant c.97C $>$ T, p.(Arg33Ter) (NM_002382.3) in a blood sample. Subsequently, given the unexpected association of neuroblastoma with a variant of the MAX gene, the presence of loss of heterozygosity (LOH) was evaluated in a formalin-fixed and paraffin-embedded sample of the neuroblastoma tumour (from a delimited area with $>50 \%$ tumour cells), using the same NGS panel, and the variant allele frequency (VAF) was $71.2 \%$, which is compatible with LOH. During the follow-up at this centre he presented with recurrence of catecholamine hypersecretion and hypertension. After multidisciplinary team review, it was decided to start palliative chemotherapy for neuroblastoma; despite chemotherapy cycles with cyclophosphamide, doxorubicin, vincristine and topotecan from 2011 to July'2013 there was a disease progression with multiple abdominal and pelvic lymphadenopathies (the largest adenopathic conglomerates with $138 \mathrm{~mm}$ located by the left iliac vessels and $100 \times 98 \mathrm{~mm}$ next to renal hilum with bilateral hydronephrosis, severe on the left side). The posterior mediastinal mass' size remained stable and was deemed unresectable; it was assumed as a probable pheochromocytoma metastasis but with no histological evidence. 
On March 2014 he was submitted to exploratory laparotomy with debulking; pathology was consistent with poorly differentiated neuroblastoma with no lymph node parenchyma identified. ${ }^{123}$ I-MIBG on April 2014 documented multiple abdominal and pelvic focus of intense uptake, mainly on the left side. ${ }^{131}$ I- MIBG therapy was performed on June'2014 with no apparent response on post-treatment MIBG scan.

He was afterwards submitted to right nephrostomy and later, on October 2014, to a double-J stent placement, as a preparation for a new surgical debulking. On the 2nd November 2014 he was admitted to the emergency department with an urosepsis with an acute on chronic kidney disease and severe hyperkalaemia. Despite initiation of broad-spectrum antibiotics, vasopressor support and emergent continuous veno-venous hemofiltration, he died 24 hours later, at the age of 31 years old.

\section{Patient 2}

In March 1995, a 32-year old male was referred to our Endocrinology outpatient clinic with complains of daily paroxysms of headaches, diaphoresis, and facial pallor for the last 6 months. A year before he was diagnosed with hypertension, but he had refused anti-hypertensive treatment. At observation he presented a class I obesity (BMI $31.5 \mathrm{~kg} / \mathrm{m}^{2}$ ), his BP was $156 /$ $96 \mathrm{mmHg}$ with a resting heart rate of $80 \mathrm{bpm}$ and an otherwise normal physical examination. He had no signs of Cushing's syndrome, such as rounded face, thin skin, easy bruising, or purple striae.

Our investigation revealed an increase in 24-hour urinary normetanephrines and metanephrines (Table 2); 1-mg overnight dexamethasone suppression test did not detect autonomous cortisol secretion. Abdominal-CT and MRI revealed bilateral round shaped adrenal lesions of $25 \mathrm{~mm}$ with a high signal intensity on T2-weighted images suggestive of pheochromocytoma and the ${ }^{123} \mathrm{I}-\mathrm{MIBG}$ showed bilateral trace uptake. Phosphocalcic metabolism, calcitonin, thyroid function (and ultrasound) were normal.

In May 1995, a right adrenalectomy and subtotal left adrenalectomy was performed. Pathology revealed adrenal hyperplasia and the genetic testing for RET mutation was negative.

At his immediate post-operative follow-up visit he presented normal blood pressure, but 3 months after surgery he relapsed with recurrence of hypertension and paroxysms associated with elevated urinary metanephrines. Abdominal-CT revealed a residual lesion on the left adrenal gland but ${ }^{123} \mathrm{I}-\mathrm{MIBG}$ showed no abnormal uptake. After discussing the treatment options with the patient, he opted to resume alpha and beta-block therapy and maintain close clinical, analytical, and imaging surveillance. In June 2000, after clinical worsening with increased frequency of paroxysms associated with retrosternal chest pain, he was submitted to totalization of left adrenalectomy; this time pathology reported a tumoral lesion of $25 \times 15 \mathrm{~mm}$ consistent with a pheochromocytoma of low mitotic index. Post-operatively he was started on glucocorticoid and mineralocorticoid hormone replacement and his anti-hypertensive drug was stopped. He has been asymptomatic and with no evidence of catecholamine hypersecretion ever since. After the identification of a deleterious MAX variant in the index case (his oldest son, patient 1), he was found to carry the same variant.

\section{Patient 3}

In 2012, a 26 years old man without significant medical or medication history was brought to our clinic for screening after identification of a MAX germline variant in his father (patient 2) and older brother (patient 1). He was overweight (BMI 29.4kg/ $\mathrm{m}^{2}$ ) but his physical examination was otherwise normal (blood pressure was $124 / 74 \mathrm{mmHg}$ and heart rate $90 \mathrm{bpm}$ ). Biochemical testing revealed a small rise in urinary normetanephrines (see Table 3) and the abdominal - CT revealed bilateral adrenal masses (22 $\mathrm{mm}$ on the right and $14 \mathrm{~mm}$ on the left) both with high density (> 10HU) but without uptake on ${ }^{123}$ I-MIBG. The genetic testing confirmed that he was a carrier of the MAX variant previously identified in the family. The patient refused surgery at the time and decided to remain on surveillance. Until 2018 the patient remained asymptomatic when he reports the onset of episodes of palpitations and is documented an elevation of blood pressure (BP $166 / 87 \mathrm{mmHg}$ ) and orthostatic tachycardia requiring treatment with a calcium channel blocker, initiated by his primary care physician. Over the years there was a progressive increase in the levels of plasma and urinary normetanephrines (Table 3) and in the dimensions of the adrenal lesions $(39 \times 27 \mathrm{~mm}$ on the right and $30 \times 25 \mathrm{~mm}$ and left

TABLE 2 | Serum and urinary catecholamines and metanephrines (reference range) at presentation and during follow-up of Patient 2.

\begin{tabular}{|c|c|c|c|c|c|c|c|c|}
\hline \multicolumn{3}{|c|}{ At presentation } & \multicolumn{6}{|c|}{ Follow-up } \\
\hline & & & June 1997 & June 1998 & March 1999 & May2000 & September 2000 & February 2020 \\
\hline \multirow[t]{2}{*}{ 24-hour urine } & Normetanephrines & $\begin{array}{c}1.36 \\
(<1 \mathrm{mg})\end{array}$ & $N M$ & $\begin{array}{c}3090 \\
(480-2424 \mathrm{nmol})\end{array}$ & $\begin{array}{c}3305 \\
(480-2424 \mathrm{nmol})\end{array}$ & $N M$ & $\begin{array}{c}2134 \\
(480-2424 \mathrm{nmol})\end{array}$ & NM \\
\hline & Metanephrines & $\begin{array}{c}0.54 \\
(<0.4 \mathrm{mg})\end{array}$ & $N M$ & $\begin{array}{c}369 \\
(264-1729 \mathrm{nmol})\end{array}$ & $\begin{array}{c}387 \\
(264-1729 \mathrm{nmol})\end{array}$ & $N M$ & $\begin{array}{c}69 \\
(264-1729 \mathrm{nmol})\end{array}$ & NM \\
\hline \multirow[t]{2}{*}{ Serum } & Normetanephrines & - & - & - & - & - & - & $\begin{array}{c}<100 \\
(<982.8 \mathrm{pmol} / \mathrm{L})\end{array}$ \\
\hline & Metanephrines & - & - & - & - & - & - & $\begin{array}{c}757 \\
(<456.3 \mathrm{pmol} / \mathrm{L})\end{array}$ \\
\hline
\end{tabular}

Laboratory results from the post-operatively period until 1997 were stated on clinical notes but could not be retrieved. Normal catecholamine secretion since the second post-operative period: the immediate post-op (September'2000) and the most recent hormonal workup are shown. Serum metanephrines were not measured at our lab before 2015.

NM, not measured. 
TABLE 3 | Serum and 24-hour urinary metanephrines (reference range), by year of patient 3.

\begin{tabular}{|c|c|c|c|c|c|c|c|c|c|c|}
\hline & \multicolumn{2}{|c|}{ At presentation } & \multicolumn{8}{|c|}{ Follow-up } \\
\hline & & & March 2014 & May 2015 & April 2016 & June 2017 & April 2018 & May 2019 & October 2019 & May 2020 \\
\hline \multirow[t]{2}{*}{ 24-hour urine } & $\begin{array}{l}\text { Normetanephrines } \\
(480-2424 \mathrm{nmol})\end{array}$ & 3130 & 3685 & 6696 & 11121 & $N M$ & 38243 & 2976 & 2002 & $N M$ \\
\hline & $\begin{array}{l}\text { Metanephrines } \\
(264-1729 \mathrm{nmol})\end{array}$ & 1170 & 1384 & 1203 & 1659 & $N M$ & 3839 & 50 & $<25$ & $N M$ \\
\hline \multirow[t]{2}{*}{ Serum } & $\begin{array}{l}\text { Normetanephrines } \\
\text { (<982.8 pmol/L) }\end{array}$ & - & - & 1390.4 & 5700 & 10398 & 11290 & 481 & 302 & 606 \\
\hline & $\begin{array}{l}\text { Metanephrines } \\
\text { (<456.3 pmol/L) }\end{array}$ & - & - & 304.1 & 548 & 753 & 729 & $<100$ & $<100$ & $<100$ \\
\hline
\end{tabular}

adrenal gland on CT scan, both with enhanced contrast on T2 sequences and no signal intensity loss on the opposed-phased image on the MRI - Figure 2). Echocardiogram had normal ventricular wall thickness with preserved ejection fraction, EKG on sinus rhythm with no signs of ischaemia.

At this point the patient accepted surgery and a laparoscopic bilateral adrenalectomy was performed on April'2019 after alpha and beta blockade. Pathology was consistent with bilateral pheochromocytoma with tumour cells reactive with chromogranin, synaptophysin and S100; proliferative index was low $(\mathrm{Ki}-67<1 \%)$.

Post-operatively he was started on glucocorticoid and mineralocorticoid replacement and his anti-hypertensive drug was stopped. Until the last appointment there was no biochemical evidence of catecholamine hypersecretion or relapse of hypertension.

\section{Patient 4}

This is the youngest son of patient 2 and in 2012 he was observed at our clinic after the identification of a MAX germline mutation in his father and his older brother. He was 14 years old, had a class I obesity (BMI $31.9 \mathrm{~kg} / \mathrm{m} 2$ ) with no other medical or medication history nor endocrine hypersecretion features and at examination his blood pressure was $132 / 67 \mathrm{mmHg}$ and heart rate of $85 \mathrm{bpm}$ with an otherwise normal physical exam. Genetic testing confirmed that he was a carrier of the same $M A X$ variant previously identified in the family. From the age of 15 years old, he underwent annual screening with 24-hour urinary metanephrines and abdominal-CT every two years with both remaining normal until 2017 (Table 4) when he presented evidence of norepinephrine hypersecretion and the abdominal$\mathrm{CT}$ revealed on the left adrenal gland, a $17 \mathrm{~mm}$ nodule with a contrast washout $>60 \%$ with no other lesions seen on the
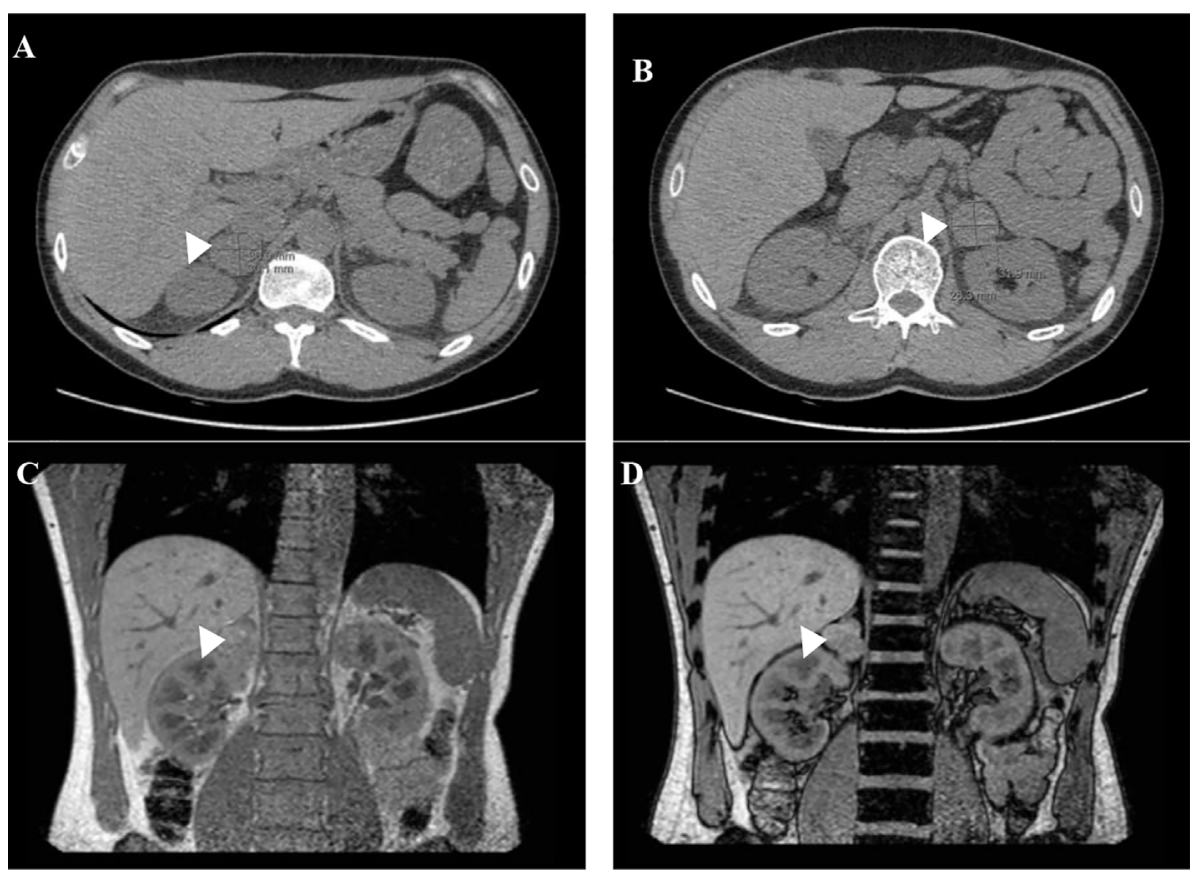

FIGURE 2 | Abdominal-CT (A, B) and MRI scan (C, D) before bilateral adrenalectomy: adrenal lesions on the right (A) and left (B) adrenal gland. Coronal in-phase (C) and out-of-phase (D) MRI images with no loss of signal in the mass. 
TABLE 4 | Serum and 24-hour urinary metanephrines (reference range), by year of patient 4.

\begin{tabular}{|c|c|c|c|c|c|c|c|c|}
\hline & & \multicolumn{7}{|c|}{ Follow-up } \\
\hline & & March 2014 & April 2016 & October 2017 & March 2018 & March 2019 & March 2020 & May 2020 \\
\hline \multirow[t]{2}{*}{ 24-hour urine } & $\begin{array}{l}\text { Normetanephrines } \\
(480-2424 \mathrm{nmol})\end{array}$ & 1011 & 1117 & 6434 & 3874 & $N M$ & $N M$ & $N M$ \\
\hline & $\begin{array}{l}\text { Metanephrines } \\
(264-1729 \mathrm{nmol})\end{array}$ & 688 & 209 & 1056 & 586 & $N M$ & $N M$ & $N M$ \\
\hline \multirow[t]{2}{*}{ Serum } & $\begin{array}{l}\text { Normetanephrines } \\
\text { (<982.8 pmol/L) }\end{array}$ & - & 644 & 1347 & 1399 & 3724 & 3383 & 1118 \\
\hline & $\begin{array}{l}\text { Metanephrines } \\
\text { (<456.3pmol/L) }\end{array}$ & - & 136 & $<100$ & 110 & 209 & 171 & 141 \\
\hline
\end{tabular}

Serum metanephrines were not measured at our lab before 2015.

NM, not measured.

contralateral gland (Figure 3). ${ }^{123} \mathrm{I}-\mathrm{MIBG}$ scan revealed no abnormal uptake but the ${ }^{68} \mathrm{Ga}$ - DOTA-NOC-PET scan documented an uptake on the left adrenal nodule. Like his older brother he chose to remain on active surveillance; although asymptomatic and with normal blood pressure, after considering the unknown risk of malignancy of a deleterious $M A X$ variant, he accepted surgery and underwent laparoscopic left adrenalectomy on March 2020 after alpha and beta blockade. Pathology was consistent with pheochromocytoma with tumour cells reactive with chromogranin, synaptophysin and S100; there was also presence of granular cytoplasmatic immunoreactivity for SDHB; proliferative index was low and PASS Score was 0/20.

The immediate post-operative period was uneventful but a month later he reported episodes of headaches with elevated blood pressure and face pallor; serum metanephrines was found slightly elevated. ${ }^{123}$ I-MIBG scan revealed no abnormal uptake.

\section{DISCUSSION}

This case series is, to our knowledge, the one with the largest number of individuals with hereditary pheochromocytoma with a deleterious $M A X$ variant in the same family. Although the association between variants in the MAX gene and hereditary

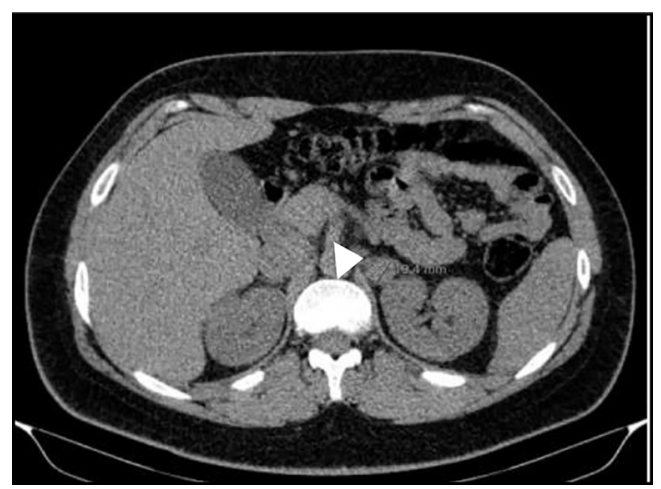

FIGURE 3 | Abdominal-CT scan before left adrenalectomy showing a 17mm nodule on the left adrenal gland. pheochromocytoma has been established during the past decade, few systematic characteristics are available (16). This report draws attention to some ill-defined features of pheochromocytoma (PPGL) and other malignancies associated with a $M A X$ variant.

Firstly, the occurrence of a potential metastatic pheochromocytoma. MAX behaves as a classical tumour suppressor gene that encodes for the MAX protein, which interacts with the MYC proto-oncogene and the MAX dimerization protein 1 (MXD1) family of proteins; this MYC/ MAX/MXD1 network regulates cell proliferation, differentiation and apoptosis $(14,17)$. Alterations in this complex promote hereditary susceptibility to neoplasia (18). Previous studies (11, $14,16,18,19)$ have presented patients with metastatic PPGL but further research is vital to determine the risk of malignancy associated with $M A X$ deleterious variants.

In addition to the frequently bilateral PPGL and the early onset, our patients' tumours secreted predominantly norepinephrine in a greater proportion than epinephrine. This biochemical phenotype is intermediate between the established epinephrine producing tumours due to NF1 and RET variants and the phenotype of norepinephrine tumours harbouring $V H L$ or $S D H B / D$ variants; this diagnostic phenotype is explained by a significant but limited capacity to produce epinephrine due to the intermediate tissue expression of mRNA for PNMT (11). An interesting aspect is the inconsistent uptake of ${ }^{123} \mathrm{I}-\mathrm{MIBG}$ at the adrenal lesions of our four reported cases. Perhaps different levels of differentiation (and consequently PNMT expression) can be held accountable for this varying accumulation.

Second, the synchronous occurrence of a neuroblastic tumour. The association of PPGL and neuroblastic tumours is uncommon and fewer cases had a genetic link. The majority of these reported cases are composite pheochromocytomaganglioneuroma and comprised an association with MEN2 (20-24), VHL (25), NF1 (26-28) and, most recently (29), one case of a new MAX gene heterozygous variant, c.299G $>C$ (p.Arg100Pro, NM_002382). Our case is, to the best of our knowledge, the first with a simultaneous PPGL and neuroblastoma presenting as two distinct entities in association with a MAX pathogenic variant. $\mathrm{LOH}$ observed in the neuroblastoma (VAF=71.2\%) supports a causal relation between the MAX germline pathogenic variant and the origin 
of this tumour The embryological common origin and the importance of MYC/MAC/MXD1 network in the development of this neural crest cells tumours are identified as the basis of this association (18). Additionally, evidence suggests that germinative and somatic inactivating $M A X$ abnormalities lead to tumour risk, namely renal oncocytoma $(18,19)$, pituitary adenomas $(30-32)$, pancreatic neuroendocrine tumours (33), small cell lung cancers (34) and Gastrointestinal Stromal Tumours (GIST) (35).

Furthermore, our work highlights the importance of firstdegree relatives targeted testing. MAX variants present with a parent of origin dependent tumorigenesis and tumour formation occurs almost exclusively through paternal transmission (36). The identification of a germline variant at a PPGL predisposing gene allows the screening of asymptomatic relatives and helps to define a follow-up plan for both mutation carriers and affected individuals (37). Expert recommendations endorse that genetic testing of children is only recommended if they will be offered surveillance during childhood years (11). Although the evidence is limited in $M A X$-related disorders, annual pre-symptomatic biochemical (normetanephrine and metanephrines and methoxytyramine) and biennial imaging (with MRI) surveillance of first-degree relatives $(11,37)$ should start from five years before the youngest age of onset in the family (11) or no later than 15 years old (38). Patient 4 started his surveillance program by the age of 15 years old but, like his older sibling (patient 3), chose to remain in active surveillance once normetanephrine hypersecretion was confirmed. Due to this mode of inheritance, it is important to analyse the mutation status of patient 3's son (and future offspring of patient 4) to ascertain who would be at risk.

At last, the extent of surgical procedure, in face of an uncertain PPGL malignancy risk, remains controversial. Regarding our patients, patient 3 postponed his surgery for six years since the diagnosis of bilateral pheochromocytoma; patient 4 also chose to remain on active surveillance until now and was submitted to a unilateral adrenalectomy. Laparoscopic total adrenalectomy has been a standard treatment for unilateral or bilateral adrenalectomy; the main sequel is adrenocortical insufficiency with subsequent need for lifelong mineralocorticoid and corticoid supplementation with risk of both Addisonian crises and excessive steroid replacement (39). Cortical sparing adrenalectomy allows more

\section{REFERENCES}

1. Lenders JWM, Eisenhofer G, Mannelli M, Pacak K. Phaeochromocytoma. Lancet (2005) 366:665-75. doi: 10.1016/S0140-6736(05)67139-5

2. Sinclair AM, Isles CG, Brown I, Cameron H, Murray GD, Robertson JW. Secondary hypertension in a blood pressure clinic. Arch Internal Med (1987) 147(7):1289-93. doi: 10.1001/archinte.147.7.1289

3. Omura M, Saito J, Yamaguchi K, Kakuta Y, Nishikawa T. Prospective study on the prevalence of secondary hypertension among hypertensive patients visiting a general outpatient clinic in Japan. Hypertension Res (2004) 27 (3):193-202. doi: 10.1291/hypres.27.193

4. Anderson GH, Blakeman N, Streeten DHP. The effect of age on prevalence of secondary forms of hypertension in 4429 consecutively referred patients. J Hypertension (1994) 12(5):609-15. doi: 10.1097/00004872-19940500000015

5. Berends AMA, Buitenwerf E, de Krijger RR, Veeger NJGM, van der HorstSchrivers ANA, Links TP, et al. Incidence of pheochromocytoma and than $50 \%$ of patients to maintain normal adrenal function at 10 years with a PPGL recurrence risk estimated between 0-21\%, with even lower reported rates (0-3\%) with more recent endoscopic approaches (39-41). Individual risk of malignancy must be taken into account when deciding this surgical procedure. Cortical sparing adrenalectomy is increasingly performed in hereditary PPGL like those with RET or VHL variants who are associated with a low risk of malignancy and high risk of bilateral PPGL (39). Castinetti $(41,42)$ reported a low recurrence risk with normal glucocorticoid function in more than $50 \%$ of the patients at 10 years. However, this approach is not systematically proposed.

In conclusion, we describe a family with a $M A X$ variant associated with hereditary PPGL with one of the patients presenting with a bilateral PPGL with synchronous neuroblastoma, the first case reported to our knowledge. Our case highlights the importance of understanding the genotypephenotype correlation in hereditary PPGL and the impact of oriented genetic testing to detect, survey and treat patients and kindreds at risk.

\section{ETHICS STATEMENT}

Written informed consent was obtained from the individual(s) for the publication of any potentially identifiable images or data included in this article.

\section{AUTHOR CONTRIBUTIONS}

DB, LF and CC co-wrote the manuscript. MA was the pathologist responsible for the diagnosis of patient 2. JL, CS and MT carried out the genetic analysis that first demonstrated the presence of the MAX gene deleterious variant for patient 2 (in 2011) and the remaining patients (in 2012). RC is the main physician of the patients; APS was the main physician of patient 1 after his referral IPOFG. LF, APS, MT and MC contributed to the revision of the manuscript. All authors contributed to the article and approved the submitted version.

sympathetic paraganglioma in the Netherlands: A nationwide study and systematic review. Eur J Internal Med (2018) 51:68-73. doi: 10.1016/ j.ejim.2018.01.015

6. Dahia PLM. Pheochromocytoma and paraganglioma pathogenesis: Learning from genetic heterogeneity. Nat Rev Cancer (2014) 14:108-19. doi: 10.1038/ nrc3648

7. Crona J, Taïeb D, Pacak K. New perspectives on pheochromocytoma and paraganglioma: Toward a molecular classification. Endocrine Rev (2017) 38:489-515. Oxford University Press. doi: 10.1210/er.201700062

8. Lenders JWM, Duh QY, Eisenhofer G, Gimenez-Roqueplo AP, Grebe SKG, Murad $\mathrm{MH}$, et al. Pheochromocytoma and paraganglioma: An endocrine society clinical practice guideline. J Clin Endocrinol Metab (2014) 99:1915-42. Endocrine Society. doi: 10.1210/jc.2014-1498

9. Plouin PF, Amar L, Dekkers OM, Fassnach M, Gimenez-Roqueplo AP, Lenders JWM, et al. European Society of Endocrinology Clinical Practice Guideline for long-term follow-up of patients operated on for a 
phaeochromocytoma or a paraganglioma. Eur J Endocrinology (2016) 174(5): G1-10. doi: 10.1530/EJE-16-0033

10. Fishbein L, Merrill S, Fraker DL, Cohen DL, Nathanson KL. Inherited mutations in pheochromocytoma and paraganglioma: Why all patients should be offered genetic testing. Ann Surg Oncol (2013) 20(5):1444-50. doi: 10.1245/s10434-013-2942-5

11. Muth A, Crona J, Gimm O, Elmgren A, Filipsson K, Stenmark Askmalm M, et al. Genetic testing and surveillance guidelines in hereditary pheochromocytoma and paraganglioma. J Internal Med (2018) 285(2): joim.12869. doi: 10.1111/joim.12869

12. Sbardella E, Cranston T, Isidori AM, Shine B, Pal A, Jafar-Mohammadi B, et al. Routine genetic screening with a multi-gene panel in patients with pheochromocytomas. Endocrine (2018) 59(1):175-82. doi: 10.1007/s12020017-1310-9

13. Pillai S, Gopalan V, Smith RA, Lam AKY. Updates on the genetics and the clinical impacts on phaeochromocytoma and paraganglioma in the new era. Crit Rev Oncology/Hematology (2016) 100:190-208. Elsevier Ireland Ltd. doi: 10.1016/j.critrevonc.2016.01.022

14. Comino-Méndez I, Gracia-Aznárez FJ, Schiavi F, Landa I, Leandro-García LJ, Letón R, et al. Exome sequencing identifies MAX mutations as a cause of hereditary pheochromocytoma. Nat Genet (2011) 43:663-7. doi: 10.1038/ ng.861

15. Neumann HP, Young WF, Krauss T, Bayley JP, Schiavi F, Opocher G, et al. Genetics informs precision practice in the diagnosis and management of pheochromocytoma. Endocrine-Related Cancer (2018) 25:T201-19. BioScientifica Ltd. doi: 10.1530/ERC-18-0085

16. Bausch B, Schiavi F, Ni Y, Welander J, Patocs A, Ngeow J, et al. Clinical characterization of the pheochromocytoma and paraganglioma susceptibility genes SDHA, TMEM127, MAX, and SDHAF2 for gene-informed prevention. JAMA Oncol (2017) 3(9):1204-12. doi: 10.1001/jamaoncol.2017.0223

17. Cascoń A, Robledo M. MAX and MYC: A heritable breakup. Cancer Res Am Assoc Cancer Res (2012) 72:3119-24. doi: 10.1158/0008-5472.CAN11-3891

18. Burnichon N, Cascoń A, Schiavi F, Morales NP, Comino-Méndez I, Abermil $\mathrm{N}$, et al. MAX mutations cause hereditary and sporadic pheochromocytoma and paraganglioma. Clin Cancer Res (2012) 18(10):2828-37. doi: 10.1158/ 1078-0432.CCR-12-0160

19. Korpershoek E, Koffy D, Eussen BH, Oudijk L, Papathomas TG, van Nederveen FH, et al. Complex MAX Rearrangement in a Family With Malignant Pheochromocytoma, Renal Oncocytoma, and Erythrocytosis. J Clin Endocrinol Metab (2016) 101(2):453-60. doi: $10.1210 /$ jc. $2015-2592$

20. Efared B, Atsame-Ebang G, Tahirou S, Mazaz K, Hammas N, El Fatemi H, et al. Bilateral pheochromocytoma with ganglioneuroma component associated with multiple neuroendocrine neoplasia type $2 \mathrm{~A}$ : A case report. J Med Case Rep (2017) 11(1):208. doi: 10.1186/s13256-017-1364-6

21. Brady S, Lechan RM, Schwaitzberg SD, Dayal Y, Ziar J, Tischler AS. Composite pheochromocytoma/ganglioneuroma of the adrenal gland associated with multiple endocrine neoplasia 2A: Case report with immunohistochemical analysis. Am J Surg Pathology (1997) 21(1):102-8. doi: 10.1097/00000478-199701000-00011

22. Matias-Guiu G. Composite phaeochromocytoma-ganglioneuroblastoma in a patient with multiple endocrine neoplasia type IIA. Histopathology (1998) 32 (3):281-2. doi: 10.1046/j.1365-2559.1998.0372g.x

23. Charfi S, Ayadi L, Ellouze S, Ghorbel R, Khabir A, Gouiaa N, et al. Phéochromocytome composite associé à une néoplasie endocrine multiple de type 2B. Annales Pathologie (2008) 28(3):225-8. doi: 10.1016/j.annpat.2008.06.003

24. Yamasaki M, Sato Y, Nomura T, Sato F, Uchino S, Mimata H. Composite paraganglioma-ganglioneuroma concomitant with adrenal metastasis of medullary thyroid carcinoma in a patient with multiple endocrine neoplasia type 2B: A case report. Asian J Endosc Surg (2017) 10(1):66-9. doi: 10.1111/ ases. 12332

25. Bernini GP, Moretti A, Mannelli M, Ercolino T, Bardini M, Caramella D, et al. Unique association of non-functioning pheochromocytoma, ganglioneuroma, adrenal cortical adenoma, hepatic and vertebral hemangiomas in a patient with a new intronic variant in the VHL gene. J Endocrinological Invest (2005) 28(2):1032-7. doi: 10.1007/BF03345345
26. Chetty R, Duhig JD. Bilateral pheochromocytoma-ganglioneuroma of the adrenal in type 1 neurofibromatosis. Am J Surg Pathology (1993) 17(8):83741. doi: 10.1097/00000478-199308000-00009

27. Lisewski D, Ryan S, Lim EM, Frost F, Nguyen H. Concomitant compostite adrenal phoechromocytoma, multipte gastric stromal tumours and pseudohermaphrodism in a patient with von Recklinghausen's disease. Int Semin Surg Oncol (2006) 3:11. doi: 10.1186/1477-7800-3-11

28. Onozawa M, Fukuhara T, Minoguchi M, Takahata M, Yamamoto Y, Miyake T, et al. Hypokalemic Rhabdomyolysis due to WDHA Syndrome Caused by VIP-producing Composite Pheochromocytoma: A Case in Neurofibromatosis Type 1 | Japanese Journal of Clinical Oncology | Oxford Academic. Japanese J Clin Oncol (2005) 35(9):559-63. doi: 10.1093/jjco/hyi139

29. Pozza C, Sesti F, di Dato C, Sbardella E, Pofi R, Schiavi F, et al. A Novel MAX Gene Mutation Variant in a Patient With Multiple and "Composite" Neuroendocrine-Neuroblastic Tumors. Front Endocrinol (2020) 11:234. doi: 10.3389/fendo.2020.00234

30. Kobza AO, Dizon S, Arnaout A. Case Report of Bilateral Pheochromocytomas due to a Novel Max Mutation in a Patient Known to Have a Pituitary Prolactinom. AACE Clin Case Rep (2018) 4(6):e453-6. doi: 10.4158/ACCR2018-0146

31. Daly AF, Castermans E, Oudijk L, Guitelman MA, Beckers P, Potorac I, et al. Pheochromocytomas and pituitary adenomas in three patients with MAX exon deletions. Endocrine-Related Cancer (2018) 25:L37-42. BioScientifica Ltd. doi: 10.1530/ERC-18-0065

32. Roszko KL, Blouch E, Blake M, Powers JF, Tischler AS, Hodin R, et al. Case Report of a Prolactinoma in a Patient With a Novel MAX Mutation and Bilateral Pheochromocytomas. J Endocrine Society (2017) 1(11):1401-7. doi: 10.1210/js.2017-00135

33. Petignot S, Daly AF, Castermans E, Korpershoek E, Scagnol I, Beckers P, et al. Pancreatic Neuroendocrine Neoplasm Associated with a Familial MAX Deletion. Hormone Metab Res (2020) 52(11):784-7. doi: 10.1055/a1186-0790

34. Romero OA, Torres-Diz M, Pros E, Savola S, Gomez A, Moran S, et al. MAX inactivation in small cell lung cancer disrupts MYC-SWI/SNF programs and is synthetic lethal with BRG1. Cancer Discov (2014) 4(3):293-303. doi: 10.1158/2159-8290.CD-13-0799

35. Pantaleo MA, Urbini M, Indio V, Ravegnini G, Nannini M, de Luca M, et al. Genome-wide analysis identifies MEN1 and MAX mutations and a neuroendocrine-like molecular heterogeneity in Quadruple WT GIST. Mol Cancer Res (2017) 15(5):553-62. doi: 10.1158/1541-7786. MCR-16-0376

36. Rednam SP, Erez A, Druker H, Janeway KA, Kamihara J, Kohlmann WK, et al. Von Hippel-Lindau and hereditary pheochromocytoma/paraganglioma syndromes: Clinical features, genetics, and surveillance recommendations in childhood. Clin Cancer Res (2017) 23(12):e68-75. doi: 10.1158/10780432.CCR-17-0547

37. Buffet A, Burnichon N, Favier J, Gimenez-Roqueplo AP. An overview of 20 years of genetic studies in pheochromocytoma and paraganglioma. Best Pract Research: Clin Endocrinol Metab (2020) 34:101416. Bailliere Tindall Ltd. doi: 10.1016/j.beem.2020.101416

38. Vermalle M, Tabarin A, Castinetti F. Hereditary pheochromocytoma and paraganglioma: screening and follow-up strategies in asymptomatic mutation carriers. Annales d'Endocrinologie (2018) 79:S10-21. doi: 10.1016/S0003-4266 (18)31234-4

39. Iacobone M, Citton M, Viel G, Schiavone D, Torresan F. Surgical approaches in hereditary endocrine tumors. Updates Surgery (2017) 69(2):181-91. doi: 10.1007/s13304-017-0451-y

40. Ferriere A, Kerlan V, Tabarin A. La chirurgie d'épargne surrénalienne: du cortex à la médulla. Annales d'Endocrinologie (2017) 78:S11-20. doi: 10.1016/ S0003-4266(17)30921-6

41. Castinetti F, Taieb D, Henry JF, Walz M, Guerin C, Brue T, et al. MANAGEMENT OF ENDOCRINE DISEASE: Outcome of Adrenal Sparing Surgery in Heritable Pheochromocytoma - PubMed. Eur $J$ Endocrinol (2016) 174(1):R9-18. doi: 10.1530/EJE-15-0549

42. Castinetti F, Qi XP, Walz MK, Maia AL, Sansó G, Peczkowska M, et al. Outcomes of adrenal-sparing surgery or total adrenalectomy in 
phaeochromocytoma associated with multiple endocrine neoplasia type 2: An international retrospective population-based study. Lancet Oncol (2014) 15 (6):648-55. doi: 10.1530/endoabs.37.S12.3

Conflict of Interest: The authors declare that the research was conducted in the absence of any commercial or financial relationships that could be construed as a potential conflict of interest.
Copyright (c) 2021 Duarte, Ferreira, Santos, Costa, Lima, Santos, Afonso, Teixeira, Carvalho and Cardoso. This is an open-access article distributed under the terms of the Creative Commons Attribution License (CC BY). The use, distribution or reproduction in other forums is permitted, provided the original author(s) and the copyright owner(s) are credited and that the original publication in this journal is cited, in accordance with accepted academic practice. No use, distribution or reproduction is permitted which does not comply with these terms. 